Portland State University

PDXScholar

Social Work Faculty Publications and

Presentations

School of Social Work

6-1-2012

\title{
What Can Physicians Learn from the Neurodiversity Movement?
}

Christina Nicolaidis

Portland State University

Follow this and additional works at: https://pdxscholar.library.pdx.edu/socwork_fac

Part of the Social Work Commons

Let us know how access to this document benefits you.

\section{Citation Details}

Nicolaidis, Christina, "What can physician's learn from the neurodiversity movement?" Virtual Mentor, AMerican Medical Association Journal of Ethics, June 2012, Volume 14, Number 6: 503-510.

This Article is brought to you for free and open access. It has been accepted for inclusion in Social Work Faculty Publications and Presentations by an authorized administrator of PDXScholar. Please contact us if we can make this document more accessible: pdxscholar@pdx.edu. 


\section{Virtual Mentor}

American Medical Association Journal of Ethics

June 2012, Volume 14, Number 6: 503-510.

OP-ED

What Can Physicians Learn from the Neurodiversity Movement?

Christina Nicolaidis, MD, MPH

When, at age 3, my son received a medical diagnosis of autism, my husband and I received a list of intensive treatments that we needed to initiate as quickly as possible and a pep talk saying that if we did these things there was a good chance we could "fix him." As a mother, I was terrified. Images of Rain Man filled my mind, quickly followed by painful memories of security officers trying to restrain my beloved 350pound adult autistic patient during a violent meltdown. As a physician and researcher, I did what I was best trained to do-I quickly took charge of the situation, scheduled consultations with every type of therapist in the city, and immersed myself in the autism literature. But I soon realized that expert opinions clashed greatly, there were no easy answers, and the evidence in support of the various therapies was extremely limited.

Interestingly, nowhere in my early foray as an "autism mom” (or in the years I had spent as a primary care physician) did anyone actually suggest learning from individuals on the autism spectrum. It was only by coincidence that I met a local autistic self-advocate who was active in the neurodiversity movement. Who could have guessed that she would change not only the way I looked at my autistic child, but also the way I practice medicine and focus my research? Now, the two of us codirect the Academic Autistic Spectrum Partnership in Research and Education (www.aaspire.org), a NIH-funded, community-academic partnership that uses a community-based participatory research (CBPR) approach to conduct research to improve the lives of individuals on the autism spectrum [1]. She and many other autistic self-advocates regularly challenge my thinking, teaching me important lessons about how to be a better mother, physician, and researcher.

Most of us have been trained to think about autism using a deficit model. Such a model, which focuses almost exclusively on impairments and limitations, ultimately leads us to see autistic individuals as broken people who are ill and, as my child's first psychologist explained, need to be fixed. The neurodiversity movement challenges us to rethink autism through the lens of human diversity [2]. It asks us to value diversity in neurobiologic development as we would value diversity in gender, race, ethnicity, religion, or sexual orientation. As opposed to only focusing on impairments, the neurodiversity model sees autistic individuals as possessing a complex combination of cognitive strengths and challenges. For example, difficulties in understanding social nuances, filtering competing sensory stimuli, and planning the tasks of daily living may be coupled with strengths in detailed thinking, memory, 
and complex pattern analysis [2]. Autistic self-advocates also ask us to see more than a $D S M$ diagnosis. Amanda Baggs, for example, says

This is about what is, not what is missing. Forget the notion of a cosmic balancing act where a god of impartiality runs around taking things away but giving one gift for every sacrifice. It is about the fact that those of us who are viewed purely as having had things taken away_as being essentially barren wastelands - are not shut out of the richness of life by being who we are. The richness we experience is not some cheap romanticized copy of the richness others experience. The richness of life is there for everyone, and whether one experiences it or not is not dependent on whether or not one is autistic [3].

The concept of neurodiversity, and the self-advocates who promote it, are often described as highly "controversial” [4-6]. At first glance, it may seem easy to write off autism-rights advocates as radical extremists [7] or to believe, as many have claimed, that they are all "high-functioning" individuals with minimal disabilities [4]. In my experience, neither is true. I will refrain from the temptation to list my partners' limitations as some form of badge of honor. However, I can assure you that many leaders in the neurodiversity movement experience significant disabilities [8].

Members of every community and leaders in every movement disagree with each other at times, and I cannot pretend that the neurodiversity movement speaks with one voice. Yet many common themes emerge from the neurodiversity movement. Below I explore how lessons from autistic self-advocates may affect how we approach our autistic patients and their families.

\section{First Do No Harm - the Dangers of “Autism Awareness”}

Several autism awareness campaigns run by parent-led organizations or universitybased psychiatry programs have incurred the wrath of the autistic self-advocacy community and its allies. In 2007, the New York University (NYU) Child Study Center ran a "public service campaign” in which autism, Asperger syndrome, and other conditions were portrayed as having kidnapped the nation's children.

Billboards and newspaper advertisements were made to look like ransom notes, with text such as, "We have your son. We will make sure he will not be able to care for himself or interact socially as long as he lives. This is only the beginning. - Autism" [9].

Similarly, in 2009, Autism Speaks released a video entitled "I am Autism," in which a satanic-sounding voice declares "I am autism" and proceeds to brag about all the destruction he will cause families [8]. An earlier Autism Speaks video, "Autism Every Day," featured a woman who longed to drive off a bridge with her autistic daughter and was only kept from doing so by the thought of what that would do to her other, nonautistic child [8].

Autistic self-advocates loudly protested against these campaigns, maintaining that they "inadvertently reinforce many of the worst stereotypes that have prevented 
children and adults with disabilities from gaining inclusion, equality, and full access to the services and supports they require” [10]. They objected to the campaigns "presenting Autistic people as useless burdens on society, on our families and on the world at large" [11]. They also warned that "too often, the idea that children with disabilities are less than human lies at the heart of horrific crimes committed against them" [10] — a tragic foreshadowing of several highly publicized murders of autistic individuals by their parents.

I understand firsthand the challenge of raising a child with a disability, but the last thing I want is for my child to be exposed to these campaigns. How would they affect his self-image? Do I want him to grow up in a world that sees him as a burden or some form of "changeling”? One physician/bioethicist openly challenged the NYU Ransom Notes campaign, saying it violated the American Medical Association Code of Medical Ethics [9]. But, on a smaller scale, in our daily communication with patients and families, how often do we, as physicians, inadvertently promote negative stereotypes, diminish our patients' self-worth, or portray them as broken individuals or burdens to others? Self-advocates remind us to reflect on the images and language we use. Communicating a strengths-based approach to autism may not only afford autistic patients the respect and dignity they deserve, but may also help family members better understand and support their loved ones.

\section{Do Not Separate “the Person” from "the Autism”}

Many autistic self-advocates maintain that being autistic cannot be separated from who they are [12]. This issue often comes up in debates about the use or rejection of person-first language, e.g., "a person with autism” rather than "an autistic person," (and hence my choice not to use person-first language when referring to autistic individuals), but it also affects how we think of our patients. Like gender, race, or sexual orientation, one's neurobiology is only one part of a person's identity and certainly not the sole defining factor of who he or she is. But by separating the autism from the person, are we encouraging our patients' family members to love an imagined nonautistic child that was never born, forgetting about the real person who exists in front of us? What would I be like if my parents had spent my childhood mourning the son they never had and trying to cure me of my femaleness? Before discussing an autism diagnosis with a parent, it is worthwhile for any physician to read Jim Sinclair's seminal 1993 essay to parents called “Don’t Mourn for Us” [13].

\section{Recognizing the Social Context of Disability}

Despite claims to the contrary, leaders in the neurodiversity movement clearly recognize autism as a disability $[8,14]$. Autistic self-advocates often vividly describe the disabilities they experience $[3,15]$. They also maintain, however, that difficulties experienced by people with disabilities are contextual and that living in a society designed for nonautistic people exacerbates the challenges experienced by autistic individuals [2]. This concept may not be intuitive to many of us trained in a medical model. But imagine a world where 99 percent of people were deaf. That society would likely not have developed spoken language. With no reason for society to curtail loud sounds, a hearing person may be disabled by the constant barrage of 
loud, distracting, painful noises that become commonplace in that world. The deaf majority might not even notice that the ability to hear could be a "strength" or might just view it as a cool party trick or savant skill.

We don't have to resort to imagination to find other cases in which medical disorders have been socially construed. Homosexuality was listed a psychiatric condition in the American Psychiatric Association’s Diagnostic and Statistical Manual until 1973, and egodystonic homosexuality was listed in the DSM until 1986 [16]. (And I vividly recall my psychiatry professor still teaching about the utility of treating homosexuality when I was in medical school in 1990.) I am not advocating for removal of autism spectrum disorders from the DSM, but for a thought-provoking, comical challenge to our medical model of autism, see the satirical website of the Institute for the Study of the Neurologically Typical, which defines neurotypic syndrome (666.00) as "a neurobiological disorder characterized by preoccupation with social concerns, delusions of superiority, and obsession with conformity" [17].

Neurodiversity, Support, Services, and Therapies Are Not Mutually Exclusive. Much of the controversy in the media about neurodiversity centers on the debate over whether or not autism can or should be "cured." The neurodiversity movement maintains that autism is a natural variation and should not be cured, an idea which greatly angers many parent advocates and scientists [6]. At some levels, the two sides of the debate may be irreconcilable. However, I believe that a great deal of the neurodiversity argument has been misunderstood. Neurodiversity advocates are arguing against the goal of "a world without autistic people" but they are not saying they don't want to "be engaged in trying to ameliorate the many challenges associated with being autistic" [14]. They advocate for increased acceptance, accommodations, and supports [14] and are very welcoming of research, therapies, and services that help them improve their quality of life [2].

As a parent, I have chosen to try a variety of accommodations, services, medications, technologies, and therapies to help my child communicate better, improve his ability to function in society, regulate his emotions, lessen his anxiety and sensory discomfort, allow him to obtain a good education, and foster positive interactions with autistic and non-autistic peers. None of these things will "cure" him of autism or make him "indistinguishable from his peers." But I am not trying to change who my son is-I just want to give him every possible opportunity to enjoy the same quality of life as my typically developing daughters. As health care professionals, it is our responsibility to advocate for access to services, therapies, and accommodations that may help improve quality of life. But it is also our responsibility to fully inform patients and families about potential treatments and interventions, many of which have relatively little documented benefit and significant risks $[18,19]$.

\section{The Fallacy of the Linear Autism Spectrum}

Some have argued that the concept of neurodiversity may make sense for the "highfunctioning" end of the autism spectrum, but not the "low-functioning" end [4]. 
Many autistic self-advocates and researchers, however, maintain that the use of concepts such as "high- and low-functioning” are inaccurate, demeaning, and potentially harmful $[8,20]$. There is just no such thing as a linear autism spectrum on which we can place individuals based on their functioning. How do you categorize an individual with minimal spoken language and very little ability to perform activities of daily living but excellent written communication skills and the ability to analyze complex patterns? How about an individual whose functioning varies tremendously from day to day or in different environments?

Many of my autistic colleagues have been categorized as both high- and lowfunctioning, with both categorizations working to take away their power or voice. If anything, there are many separate spectra related to, for example, spoken language, written communication, adaptive skills, different types of intelligence, need for consistency, sensory processing, and so on, with individuals moving to different parts of each spectrum at different points in time.

As health care professionals, we must resist the temptation to categorize people as high- or low-functioning, inasmuch as such categorizations only serve to inadvertently harm our patients. We risk unnecessarily depriving patients categorized as "low-functioning" of their self-determination and opportunities to reach their potential. Similarly, we often deprive our patients categorized as "high-functioning" of necessary supports and services, or we make dangerously false assumptions about their ability to understand what we say or carry out our recommendations. Instead, we must try to understand an individual's complex combinations of strengths and challenges, as well as the potential for wide variations in functioning. Doing so is necessary to promote self-determination and increase the effectiveness of our care.

\section{Including Autistic Individuals in Research about Autism}

Prior to becoming involved with the autistic self-advocacy community, I predominantly conducted research to improve the health care of other marginalized communities, including African Americans, Latinos, and domestic violence survivors. When I first started listening to autistic self-advocates, I was struck by the strong parallels between their frustrations with research and the well-recognized criticism of traditional research from members of ethnic and racial minority groups. They pointed to a misalignment between academic and community research priorities, lack of inclusion in the research process, inadequate informed consent, threats to study validity due to poor understanding of participants' experiences, dehumanizing and stigmatizing language, and use of findings to advance agendas that oppose community values.

My community partners and I thus founded the Academic Autistic Spectrum Partnership in Research and Education (AASPIRE, www.aaspire.org) to promote the inclusion of autistic individuals in the research process. Using a community-based participatory research approach, community members influence each stage of the research process from choosing the research questions to ensuring that our consent materials, protocols, and data collection instruments are accessible to autistic 
participants to interpreting data and disseminating findings. Including autistic individuals and family members as equal partners in the research process is not always easy, but together we have developed many structures and processes to ensure effective collaboration [1]. I believe the community members' involvement on the team has greatly enhanced the quality of our research and the validity of our findings. I strongly encourage others to find ways to effectively partner with autistic self-advocates when conducting research about autism.

\section{Providing Optimal Health Care to Individuals on the Spectrum}

Our AASPIRE research has largely aimed at improving the health care experiences of adults on the autism spectrum. Our initial study showed significant disparities in health care outcomes between autistic and nonautistic adults [21]. We are now developing an interactive health care toolkit for autistic adults, supporters, and primary care clinicians. While our work is still in progress, preliminary findings point to many potential strategies and accommodations that health care professionals can use to improve communication, help minimize sensory challenges, reduce anxiety, foster shared decision-making, and improve patient self-management. In the meantime, probably the best thing a clinician can do is explore what accommodations each patient needs and what strategies the patient and his or her supporters feel may best facilitate quality health care.

\section{Conclusions}

Who knows what the future will bring? Maybe research will discover a "cure" for autism. Maybe scientists will identify an autism gene and parents will choose to abort all autistic fetuses before they are born. Maybe we will find ways to better accommodate and support autistic individuals so that they are afforded the same opportunities as typical peers, while maintaining their autistic strengths and differences. Maybe we will look back at our current understanding of autism and shudder at our many misconceptions. Which future do you hope for? Regardless of how each of us answers that question, I believe it is our responsibility to try to understand our patients as well as possible, to value them as human beings deserving of our full respect, to recognize their strengths and the richness of their existence, to minimize the harm caused by negative, dehumanizing images and concepts, and to accommodate their needs as well as possible. I cannot possibly do justice to the many voices of autistic individuals, but I hope my random musings entice you to further explore their world. Let them challenge your thinking-who knows what you may learn? 


\section{References}

1. Nicolaidis C, Raymaker D, McDonald K, et al. Collaboration strategies in nontraditional community-based participatory research partnerships: lessons from an academic-community partnership with autistic self-advocates. Prog Community Health Partnersh. 2011;5(2):143-150.

2. Robertson SM. Neurodiversity, quality of life, and autistic adults: shifting research and professional focuses onto real-life challenges. Disabil Stud Q. 2010;30(1). http://dsq-sds.org/article/view/1069. Accessed May 18, 2012.

3. Baggs A. Cultural commentary: up in the clouds and down in the valley: my richness and yours. Disabil Stud Q. 2010;30(1). http://dsqsds.org/article/view/1052/1238. Accessed May 18, 2012.

4. Jaarsma $P$, Welin S. Autism as a natural human variation: reflections on the claims of the neurodiversity movement. Health Care Anal. 2012;20(1):20-30.

5. Neurodiversity. Wikipedia. http://en.wikipedia.org/wiki/Neurodiversity. Accessed May 14, 2012.

6. Harmon A. Nominee to disability council is lightning rod for dispute on views of autism. New York Times. March 27, 2010; A16.

7. Doherty HL. Neurodiversity's extremist autism cure opponents — by what right do they object? Facing Autism in New Brunswick. November 11, 2009. http://autisminnb.blogspot.com/2009/11/neurodiversitys-extremist-autismcure.html. Accessed May 14, 2012.

8. Savarese ET, Savarese RJ. The superior half of speaking: an introduction. Disabil Stud Q. 2010;30(1). http://dsq-sds.org/article/view/1062/1230. Accessed May 18, 2012.

9. Kras JF. The "ransom notes" affair: when the neurodiversity movement came of age. Disabil Stud Q. 2010;30(1). http://dsq-sds.org/article/view/1065. Accessed May 18, 2012.

10. Ne'eman A. An open letter on the NYU ransom notes campaign. http://www.petitiononline.com/ransom/petition.html. Accessed May 14, 2012.

11. Ne'eman A. Help us fight back against Autism Speaks' attempts to speak for us! 2009. http://autisticadvocacy.org/2009/09/help-us-fight-back-againstautism-speaks-attempts-to-speak-for-us/. Accessed May 14, 2012.

12. Sinclair J. Why I dislike "person first” language. 1999. http://web.archive.org/web/20090210190652/http://web.syr.edu/ jisincla/per son_first.htm. Accessed January 4, 2011.

13. Sinclair J. Don’t mourn for us. 1993. http://www.autreat.com/dont_mourn.html. Accessed May 14, 2012.

14. Ne'eman A. The future (and the past) of autism advocacy, or why the ASA's magazine, The Advocate, wouldn't publish this piece. Disabil Stud Q. 2010;30(1). http://dsq-sds.org/article/view/1059/1244. Accessed May 18, 2012.

15. Pentzell N. Cultural commentary: dissed ability: grappling with stereotypes and the internalized oppression of Babyliss. Disabil Stud Q. 2010;30(1). http://dsq-sds.org/article/view/1054/1241. Accessed May 18, 2012. 
16. Drescher J. A history of homosexuality and organized psychoanalysis. $J$ Am Acad Psychoanal Dyn Psychiatry. 2008;36(3):443-460.

17. ISNT. Institute for the Study of the Neurologically Typical. http://isnt.autistics.org/. Accessed May 14, 2012.

18. McPheeters ML, Warren Z, Sathe N, et al. A systematic review of medical treatments for children with autism spectrum disorders. Pediatrics. 2011;127(5):e1312-e1321.

19. Warren Z, McPheeters ML, Sathe N, Foss-Feig JH, Glasser A, VeenstraVanderWeele J. A systematic review of early intensive intervention for autism spectrum disorders. Pediatrics. 2011;127(5):e1303-e1311.

20. Murray S. Autism functions/the function of autism. Disabil Stud Q. 2010;30(1). http://dsq-sds.org/article/view/1048. Accessed May 18, 2012.

21. Nicolaidis C, Raymaker D, McDonald K, et al. Healthcare disparities experienced by adults on the autistic spectrum. Paper presented at: Annual Meeting of the Society for General Internal Medicine; May 2010; Phoenix, Arizona.

Christina Nicolaidis, MD, MPH, is an associate professor in the Departments of Medicine and Public Health and Preventive Medicine at the Oregon Health and Science University (OHSU) in Portland. Dr. Nicolaidis co-directs the Academic Autism Spectrum Partnership in Research and Education (AASPIRE), directs the Samuel Wise Fellowship in General Internal Medicine at OHSU, and serves as a standing member of the NIH Mental Health Services study section. She also teaches and practices internal medicine, supervising residents and students in both the inpatient and outpatient setting.

\section{Related in VM}

Can Parents of a Child with Autism Refuse Treatment for Him? November 2010

When Diagnosis Is a Double-Edged Sword, December 2011

The Spectrum of Autism-from Neuronal Connections to Expressive Behavior, November 2010

\section{Disclaimer}

The opinions expressed in this article are those of Dr. Nicolaidis. They do not reflect the opinions of any the institutions, organizations, or funding agencies with which she is affiliated.

The viewpoints expressed on this site are those of the authors and do not necessarily reflect the views and policies of the AMA.

Copyright 2012 American Medical Association. All rights reserved. 